\title{
Anti-Fibrotic Activity of an Antimicrobial Peptide in a Drosophila Model
}

\author{
Dilan Khalili $^{\mathrm{a}}$ Christina Kalcher $^{\mathrm{a}} \quad$ Stefan Baumgartner $^{\mathrm{b}} \quad$ Ulrich Theopold $^{\mathrm{a}}$ \\ aDepartment of Molecular Biosciences, The Wenner-Gren Institute (MBW), Stockholm University, Stockholm,

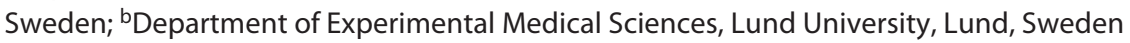

\section{Keywords}

Fibrosis · Antimicrobial peptides · Insect immunity · Innate immunity $\cdot$ Extracellular matrix

\begin{abstract}
Fibrotic lesions accompany several pathological conditions, including tumors. We show that expression of a dominantactive form of the Ras oncogene in Drosophila salivary glands (SGs) leads to redistribution of components of the basement membrane (BM) and fibrotic lesions. Similar to several types of mammalian fibrosis, the disturbed BM attracts clot components, including insect transglutaminase and phenoloxidase. SG epithelial cells show reduced apicobasal polarity accompanied by a loss of secretory activity. Both the fibrotic lesions and the reduced cell polarity are alleviated by ectopic expression of the antimicrobial peptide drosomycin (Drs), which also restores the secretory activity of the SGs. In addition to extracellular matrix components, both Drs and F-actin localize to fibrotic lesions.

(c) 2021 The Author(s)

Published by S. Karger AG, Basel
\end{abstract}

\section{Introduction}

Extracellular matrices (ECMs) are highly specialized three-dimensional, tissue- and stage-specific structures, which surround cells. Much of our understanding of the ECM structure and dynamics has been obtained by study- ing model organisms $[1,2]$. The ECM is composed of fibrous as well as nonfibrous proteins and of proteoglycans. Fibrous collagen and laminin (lam) form 2 extracellular networks in part through self-assembly [3, 4]. Nonfibrous proteins of the ECM including nidogen $(\mathrm{Ndg})$ and the proteoglycan perlecan (Pcan) mediate the interaction between the collagen- and lam networks [4]. Formation of the ECM is influenced by the underlying cells via receptors such as dystroglycan, syndecans, and integrins, which mediate contact between the cells and the ECM [3-5]. Mutual cell-ECM interactions influence cell adhesion, migration, proliferation, apoptosis, and cell differentiation during the development. In recent years, it has been increasingly recognized that instead of being a stable structure, the ECM is a highly dynamic matrix, which undergoes constant turnover both during the development and as part of physiologic adaptations [3-5]. During the development, the ECM directs morphogenetic processes, for example, in the intestine, the lungs, and the mammary and submandibular (salivary) glands $[3,5]$. Physiological responses include rapid repair upon tissue damage, which restores cellular and ECM integrity. In contrast, if unchecked, ECM remodeling in humans may promote pathological states, such as osteoarthritis, fibrosis, and progression toward cancer [3, 5-7] and may impede the delivery of drugs [8]. Fibrosis affects different organs, including the skin, liver, kidney, heart, and lungs [9]. Fibrotic triggers include genetic disorders, mechanical stimuli, such as asbestos, poorly controlled diabetes
(C) 2021 The Author(s)

Published by S. Karger AG, Basel

This is an Open Access article licensed under the Creative Commons Attribution-NonCommercial-4.0 International License (CC BY-NC) (http://www.karger.com/Services/OpenAccessLicense), applicable to the online version of the article only. Usage and distribution for commercial purposes requires written permission.
Correspondence to:

Ulrich Theopold, uli.theopold@su.se 
and hypertension, tissue dysplasia, such as in tumors as well as persistent infections [10]. Pulmonary fibrosis may be of unknown origin (idiopathic, [11]) or a consequence of infections such as during severe cases of COVID-19 [12]. Fibrotic lesions are often characterized by an unabated activation of wound healing [10]. Chronic activation may occur during the (1) initial hemostatic phase, the subsequent (2) recruitment of the cells of innate and adaptive immunity, or (3) during the remodeling and restoration of tissue integrity. The last stage includes the migration and differentiation of fibroblasts into myofibroblasts [9]. Fibroblastic pathologies include increased production of ECM components, increased stiffness of the ECM, as well as chronic immune activation and inflammation $[3,4,8,9]$. ECM dysregulation often affects tissue function and may lead to complete organ failure and ultimately to death $[4,10,13,14]$.

Effector mechanisms of insect innate immune systems comprise both soluble and cellular reactions $[15$, 16]. Soluble mediators are released from immune-competent organs, primarily the fat body but also the gut, the tracheae, and the salivary glands [15, 17-19]. Among the most strongly induced soluble mediators are several classes of antimicrobial peptides (AMPs), with both antibacterial and antifungal activities [15]. One example for the latter is the antifungal peptide Drosomycin (Drs, [20]). Cellular immunity relies on hemocytes and immune cells in the hemolymph, which in noninfected Drosophila melanogaster comprise plasmatocytes and crystal cells $[15,21,22]$. Plasmatocytes have been likened to macrophages, although recent single-cell RNA sequencing revealed a high level of diversity among plasmatocytes $[16,22-24]$. They are also key players during insect hemostasis and release coagulation factors, which help to seal wounds and prevent dissemination of microbial intruders [25]. Coagulation factors in insects include transglutaminase, a homolog of the mammalian clotting factor XIIIa [22, 26, 27]. Crystal cells contain inactive precursors of the enzyme phenoloxidase (prophenoloxidase, PPO), which is activated upon infection and wounding and leads to the production of intermediates with anti-

Fig. 1. Dysplasia promotes formation of fibrosis and the loss of epithelial organization. a PBS and PBST-treated wild type and Ras $^{V 12}$-expressing glands were stained with antibodies against SPARC, Lam, Ndg, Pcan, and actin. b-c Quantification of collagen IV (Vkg-GFP) thickness in $w^{1118}$ and Ras ${ }^{V 12}$ glands shows an increase in BM thickness $(p<0.0358)$. d Extracellular F-actin accumulates on the surface of the Ras ${ }^{V 12}$ glands (detected by $\mathrm{Ph}$ ). $\mathbf{e - g}$ The intensity of SPARC and actin covary $\left(\mathbf{e}, \mathbf{f} ; R^{2} 0.4524\right)$ and $(\mathbf{g})$ bacterial and cross-linking activity at wound sites, and ultimately to the production of melanin [22]. Melanization is also the final part of responses against large numbers of bacteria (nodule formation) and against larger intruders such as wasp eggs (encapsulation, $[15,16]$ ). Nodule formation and encapsulation have been likened to the formation of granulomas in vertebrates $[25,28$, 29]. Melanization is also observed as a consequence of deregulation of immunity and as part of the response against aberrant self-tissues similar to autoimmune reactions in mammals. Mutants that display endogenously driven melanization have been named "melanotic tumor mutants," although the underlying mechanism is not necessarily linked to mutations in tumor-promoting genes [30].

Dysregulation of the ECM with similarities to fibrosis has been induced experimentally in Drosophila and the effects on immunity studied [31]. In flies, one particular kind of ECM, the basement membrane (BM) covers all internal organs and separates them from the hemolymph in the open circulatory system. The BM is created through the release of its components from the fat body into the hemolymph and subsequent deposition onto the basal site of tissues, including the fat body itself. Hemocytes contribute to BM formation or its repair [3237], although the relative contribution of hemocytes versus fat body may be variable [38]. In one study, the formation of BM deposits with similarity to fibrotic lesions was induced in the fat body by the plasma membrane overgrowth or alternatively through increased secretion of immune effectors. Both scenarios led to a damage response, including melanization [31]. Melanization was also observed by simultaneous disruption of the BM and loss of cell polarity [39]. Similarly, the Drosophila ECM protein SPARC (Secreted Protein, Acidic and Rich in Cysteine, also called BM40) was found to contribute to age-related cardiac fibrotic deposits, associated with reduced life span in flies [40]. Here, we show that ECM components are dysregulated in flies that express a dominant-active oncogene $\left(\mathrm{Ras}^{\mathrm{V} 12}\right)$ in the salivary glands (SGs; [29]). SGs have so far been mostly

colocalize $\left(R^{2} 0.3961\right)$. ROI is indicated in yellow and displayed as an unprocessed $\mathrm{z}$-stack showing moderate colocalization of SPARC (red) and phalloidin (green). The scale bars (a, d, e) represent $100 \mu \mathrm{m}$. PBS, phosphate buffered saline; SPARC, Secreted Protein, Acidic and Rich in Cysteine; Lam, laminin; Ndg, nidogen; Pcan, perlecan; Ph, phalloidin; BM, basement membrane; ROI, region of interest.

(For figure see next page.) 

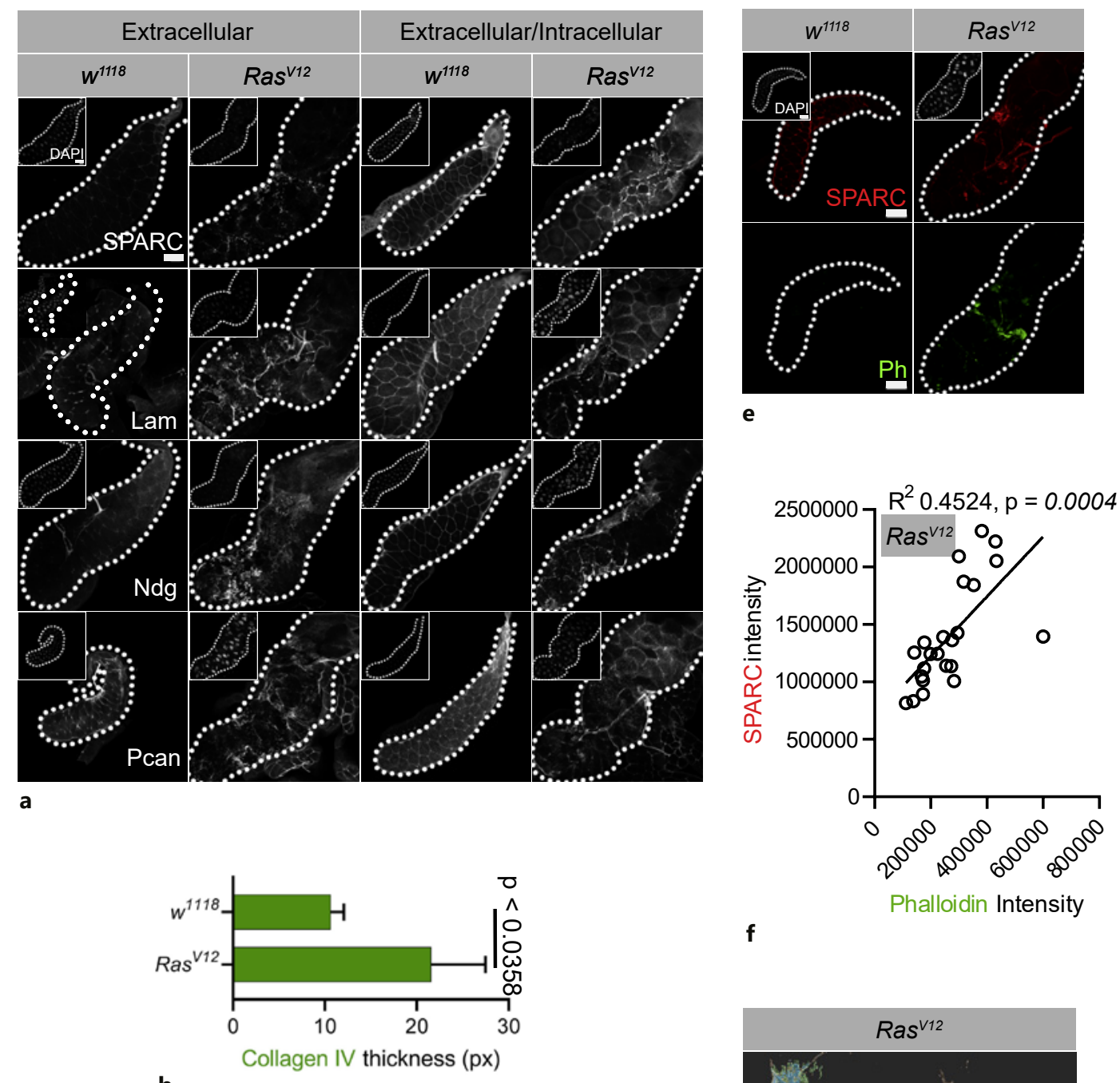

f
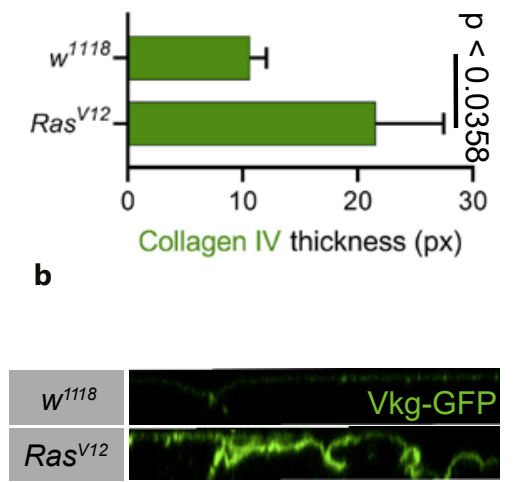

c
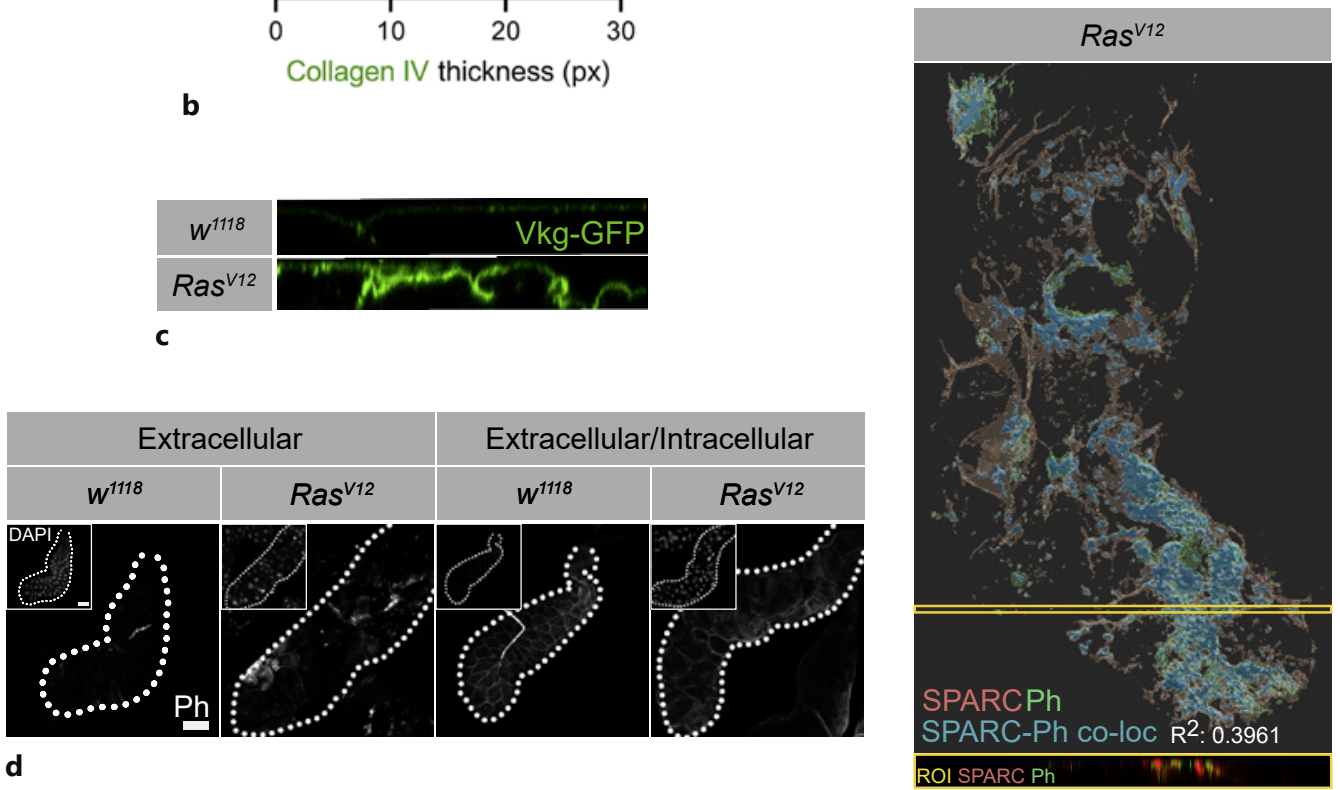

g 


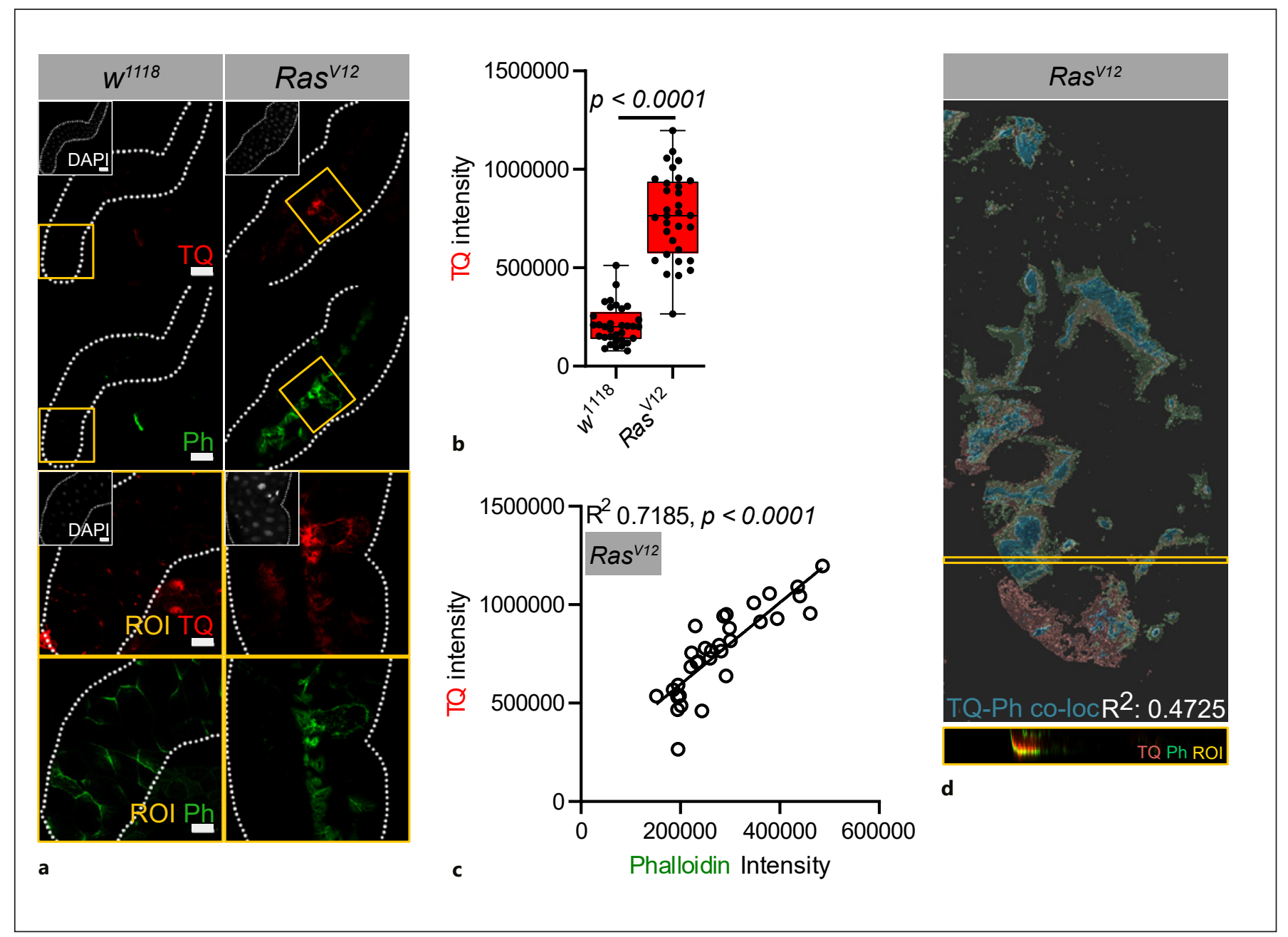

Fig. 2. Activation of TG activity in $\mathrm{Ras}^{\mathrm{V} 12}$-expressing glands. a, b Higher TG activity (TQ in red) was detected on Ras ${ }^{V 12}$-expressing SGs in comparison to $w^{1118}$ SGs (quantified in b). Upper ROI insets (a: yellow) are magnified in the lower panel. c TG (red) activity covaries with $\mathrm{Ph}$ (green, $p<0.0001$ ). d Colocalization analysis showed a moderate overlap between TQ and $\mathrm{Ph}$ (turquoise, $R^{2}$
0.4725). ROI inset (d: yellow) displays an unprocessed z-stack of TQ (red) and Ph (green). The scale bars in (a) correspond to 100 $\mu \mathrm{m}$ ( 2 upper panels) and $50 \mu \mathrm{m}$ (ROI). TG activity, transglutaminase activity; ROI, region of interest; SGs, salivary glands; $\mathrm{Ph}$, phalloidin. studied as models for organ development [41-44] and for innate immunity [45]. Proper secretion of salivary glue proteins and other mucin-type secretions in preparation for pupation is indicative of normal SG function [44] and is expected to be negatively affected by the formation of fibrosis [4], and this is what we observe. The fibrotic phenotype is strongest in the distal, secretory part of the SGs where ECM dysregulation coincides with the recruitment of transglutaminase and phenoloxidase and of hemocytes. In contrast, the proximal part of SGs displays an almost normal histology despite strong activation of AMPs, most notably the AMP Drs. Due to the similarities to fibrotic lesions in mammals, we refer to the regions with dysregulated ECM deposition concomitant with inflammatory reactions [46] as fibrotic deposits, although we acknowledge some differences to mammalian fibrosis [47]. Surprisingly, forced SG-wide expression of Drs, including distal SGs, strongly reverted fibrosis and restored tissue integrity in distal SGs and secretory activity to almost normal levels. This indicates that depending on the type of response, innate immune reactions may have pro- and anti-fibrotic consequences and establishes AMPs as regulators of tissue homeostasis. 
Fig. 3. Ras $^{V 12}$ glands display a partial loss of epithelial character and loss of secretion. (a) In Ras $^{V 12}$ SGs, ß-integrin is lost from the basolateral site, F-actin (Ph) cuboidal distribution is lost and Dlg is absent from the apical site, in comparison to $w^{1118}$ glands. b, c Sgs3 intensity is reduced in $\mathrm{Ras}^{V 12}$ glands detected by Sgs3-GFP (b, quantified in c). d Western blot analysis shows a higher amount of Eig71Ee in $w^{1111}$ than $\operatorname{Ras}^{V 12}$ SGs $(p=0.002, N=3, \mathbf{d})$. Scale bar represent in (a) $50 \mu \mathrm{m}$ and in (b) 100 $\mu \mathrm{m}$. SGs, salivary glands; Dlg, disc-large; Sgs3, salivary glands secreted protein $3 ; \mathrm{Ph}$, phalloidin.

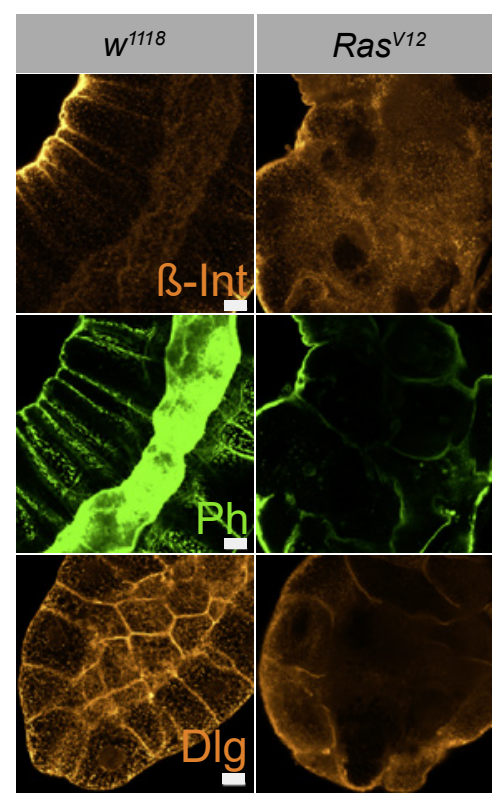

a

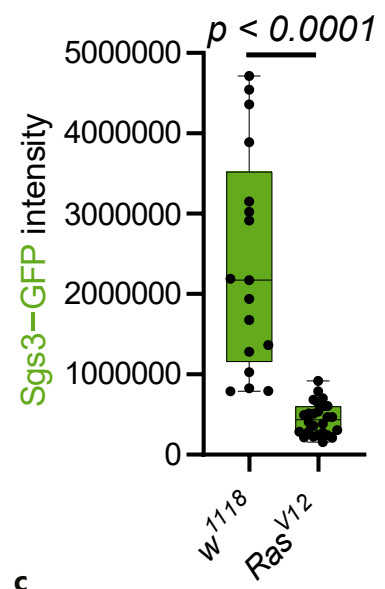

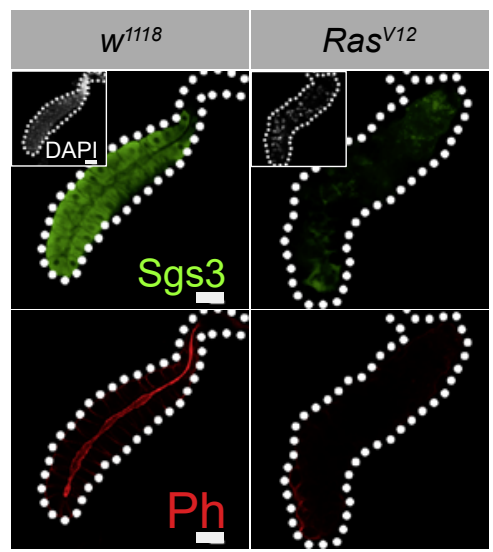

b

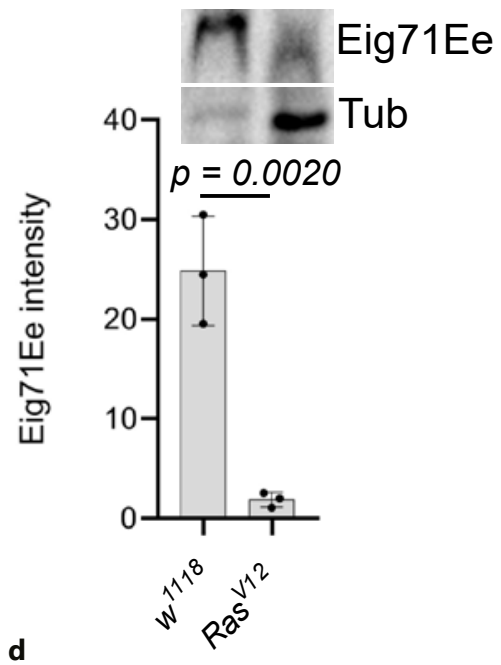

\section{Material and Methods}

Fly Strains and Sample Preparation

$w^{1118}$,Beadex ${ }^{M S 1096}$-Gal4 (Referred here as Bx: 8860/Bl), $w^{1118}$, $w^{1118} ;$;UAS-Ras $^{V 12}$ (4847/Bl), $w^{1118} ;$;UAS-Drs (Drs-OE: overexpression [46], w1118; $\mathrm{Vkg}^{\mathrm{G} 00454} / \mathrm{CyO}$.GFP [48], UAS-Drs-HA [49], $B x, m C D 8:: R F P[46]$ and Sgs3-GFP (5884/Bl) (see also online suppl. Table 1; for all online suppl. material, see www.karger.com/ doi/10.1159/000516104).

Flies were cultured in $25^{\circ} \mathrm{C}, 12$-h dark/light cycle room. Female virgins were collected for 5 days and crossed to the respective male on day 7. Progeny larvae were grown as described in Ref [46]. Ten to twenty salivary gland pairs were fixed in $4 \%$ PFA for $20 \mathrm{~min}$. Samples subjected for extracellular staining were washed $3 \times 10$ min with $1 x$ phosphate buffered saline (PBS).
Samples used to stain for intracellular expression were washed 3 $\times 10$ min with PBS-T (PBS with Triton X-100: $1 \%$ ) before staining.

\section{Production of Antibodies}

GM02366 (Flybase, [50]) coding for Drosophila SPARC was used as a template for PCR amplification using Takara Ex Taq polymerase (Takara Biomedicals) according to the manufacturer's instructions. 5 and $3^{\prime}$ primers equipped with suitable restriction enzymes created a PCR fragment spanning the complete open reading frame lacking the SPARC signal peptide that was subsequently ligated in-frame downstream of the mouse BM-40 signal peptide of the episomal expression vector pCEP-Pu [51]. After verification of the sequence, the expression vector was used to transfect human 293-EBNA cells (Invitrogen), and serum-free 
medium was collected for protein purification according to established methods [51]. Immunization of rabbits, affinity purification of antibodies, and ELISA titration followed the standard protocols [52].

\section{Immunohistochemistry}

Antibodies against SPARC (1:3,000: this report), Nidogen $(1: 2,000)$ [53], Lam $(1: 2,000)$ [54], and Pcan $(1: 2,000)$ [55] were incubated overnight $(\mathrm{ON})$ at $4^{\circ} \mathrm{C}$ either in PBS (non-permeabilized) or PBS-T (permeabilized). PPO1 (1:500), PPO2 (1:250), and tiggrin (1:500 [56], a kind gift by A. Simmonds, Alberta) were stained in PBS at $4^{\circ} \mathrm{CON}$. Anti-ß-integrin (1:200, DSHB \#CF.6G11) and Anti-Dlg (1:50, DSHB \#4F3, [44]) was incubated at $4^{\circ} \mathrm{C}, \mathrm{ON}$ in PBS-T. Anti-HA (1:3,000, Thermofisher \#5B1D10) was preincubated with fixed Ras $^{V 12}$ salivary glands for $1 \mathrm{~h}$ at room temperature (RT) in PBS-T and subsequently incubated with the samples for $1 \mathrm{~h}$ at RT. Samples were washed $3 \times 10 \mathrm{~min}$ with PBS/PBS-T and incubated with secondary antibody Anti-Rabbit-568 (1:500, Thermofisher \#A21069), Anti-Rabbit-488 (1:100, Thermofisher \#A11008) or Anti-Mouse-546 (1:500, Thermofisher \#A11030), DAPI (1:500, Sigma-Aldrich D9542), and Phalloidin-488/546 (1:500, Sigma-Aldrich \#A12379 and \#A22283, respectively) for $1 \mathrm{~h}$ at RT, washed $3 \times 10$ min with PBS or PBS-T before mounting in Fluoromount-G.

\section{Transglutaminase Activity}

Salivary glands were fixed in 4\% PFA for 20 min and washed 3 $\times 10$ min with PBS at RT. The glands were incubated with TQ, an antibody that recognizes isopeptide ( $\varepsilon$-[ $\nabla$-L-glutamyl]-L-lysine) generated by transglutaminase (1:100, Covalab \#mab0012), in PBS at $4^{\circ} \mathrm{C}$ ON. Samples were washed $3 \times 10 \mathrm{~min}$ in PBS. Primary antibody was detected with Anti-Mouse-546 (1:500, Thermofisher \#A11030) for $1 \mathrm{~h}$ at RT. Thereafter, the samples were washed $3 \times$ $10 \mathrm{~min}$ in PBS and subsequently mounted in Fluoromount-G. Image acquisition and analysis is described below.

\section{Image Acquisition and Analysis}

Whole SGs were photographed with a Zeiss AxioscopeII microscope and images were exported as TIF files. The intensity was measured of the whole gland with ImageJ (ver. 1.52n). For covariation of the intensity, the signal (SPARC, TQ, PPO1, PPO2, or HA) of the individual salivary glands was plotted against the phalloidin intensity signal of the same gland. Representative images were captured using a confocal Zeiss LSM780 microscope. Final figures were made on Affinity Designer (version 1.7.3). Zstack images were taken with LSM780 (objective $40 x / 1 \mathrm{~m} 3$ Oil and 63x/1.40 Oil DiC M27) and colocalization analysis was analyzed on Imaris (version $1.52 \mathrm{n}$, coloc module). Statistics was performed in GraphPad (8.3.0), including D'Agostino for normal distribution, unpaired $t$ test, Pearson's correlation, and linear regression.

Fig. 4. Drs expression prevents fibrosis in $\operatorname{Ras}^{V 12}$ glands. a Drs$O E, \operatorname{Ras}^{V 12}$ leads to reduced expression of SPARC and F-actin $(\mathrm{Ph}$, quantified in b: $p=0.0004$ ) compared to Ras ${ }^{V 12}$ SGs. c, d Collagen IV thickness was restored to control levels in Drs-OE, Ras ${ }^{V 12}$ glands, in comparison to $\operatorname{Ras}^{V 12}$ SGs $(p<0.001)$. e, $\mathbf{f}$ TG activity (TQ, quantified in $\mathbf{f}: p=0.0093$ ) and PPO1 (e, quantified in $\mathbf{g :} p>$
Basal Membrane Thickness Analysis

$Z$-stacked images were analyzed on a $Y$ - $Z$ plane in ImageJ (ver. $1.52 \mathrm{n})$. The "straight line" tool was used to measure the thickness of Collagen IV (Vkg-GFP), presented in pixels. Ten measurements across a $Y-Z$ plane were averaged per salivary gland. A minimum of three salivary glands per genotype were measured. An unpaired $t$ test was performed in GraphPad (8.3.0).

\section{Reverse-Transcription Quantitative PCR}

RNA extraction, cDNA synthesis, and qPCR analysis were performed as described in Ref [46]. qPCR was performed on 3 independent replicas targeting Rpl32, Sgs3, and Eig73Ee. Primer sequence for Rpl32: $5^{\prime}$-CGGATCGATATGCTA-3' and $5^{\prime}$-CGACGCACTCTGTTG-3', Sgs3: 5'-GTGCTAAGAGGGATGCACTGT- $3^{\prime}$ and $5^{\prime}$-AGACGCATTGACGGATCTTGC- $3^{\prime}$, and Eig73Ee: $5^{\prime}$-CTAACTGTGGTCTGCTTAGTGG-3' and $5^{\prime}$-CAACGCTTTCTCAATTACCTCCA-3'.

\section{Western Blot}

Salivary glands from 10-staged larvae were dissected and homogenized with a micropestle in Laemmli buffer supplemented with cOmplete (Roche) and DTT. Thereafter, the samples were incubated for $10 \mathrm{~min}$ at $80^{\circ} \mathrm{C}$. Ten microliters of lysate was loaded onto a $6 \%$ SDS gel. Proteins were transferred to a $0.45-\mu \mathrm{m}$ nitrocellulose membrane (Biorad: \#1620115) and subsequently incubated with PNG Peroxidase (Sigma-Aldrich \#L7759, 1:1,000) and antitubulin (1:5000, AbCam \#184970) for $1 \mathrm{~h}$ at RT. Tubulin was detected with HRP-conjugated anti-mouse incubated for $30 \mathrm{~min}$ at RT. Bands were detected with ChemiDoc (Biorad) and analyzed for intensity with ImageLab (version 5.2.1). The intensity of 150$\mathrm{kDa}$ bands was normalized to tubulin. Unpaired $t$ test was then applied. Coomassie staining was performed according to the protocol (Sigma-Aldrich \#B2025).

\section{Results}

\section{A Fibrosis Model in Drosophila Salivary Glands}

We had previously shown that expression of a dominant-active version of Ras $\left(\operatorname{Ras}^{V 12}\right)$ driven by BeadexGal4 (referred here as $\operatorname{Ras}^{V 12}$ ) in SGs $[29,57]$ leads to an increase in the signal intensity, redistribution, and disruption of collagen IV in the BM [46]. Here, we initially analyzed the expression of SPARC, which is known to directly interact with collagen IV and found that - similar to collagen IV - its signal intensity increased in $\mathrm{Ras}^{\mathrm{V} 12}$ SGs (Fig. 1a; quantified in online suppl. Fig. 1a). The distribution of SPARC and 3 additional ECM components

0.0001), in comparison to $\operatorname{Ras}^{V 12}$ SGs was also reduced upon coexpression of Drs. Scale bars in (a, d) represent $100 \mu \mathrm{m}$. Drs$\mathrm{OE}, \mathrm{Ras}^{\mathrm{v} 12}$, drosomycin overexpression in $\mathrm{Ras}^{\mathrm{V} 12}$ glands; SPARC, Secreted Protein, Acidic and Rich in Cysteine; SGs, salivary glands; TG activity, transglutaminase activity, $\mathrm{Ph}$, phalloidin.

(For figure see next page.) 

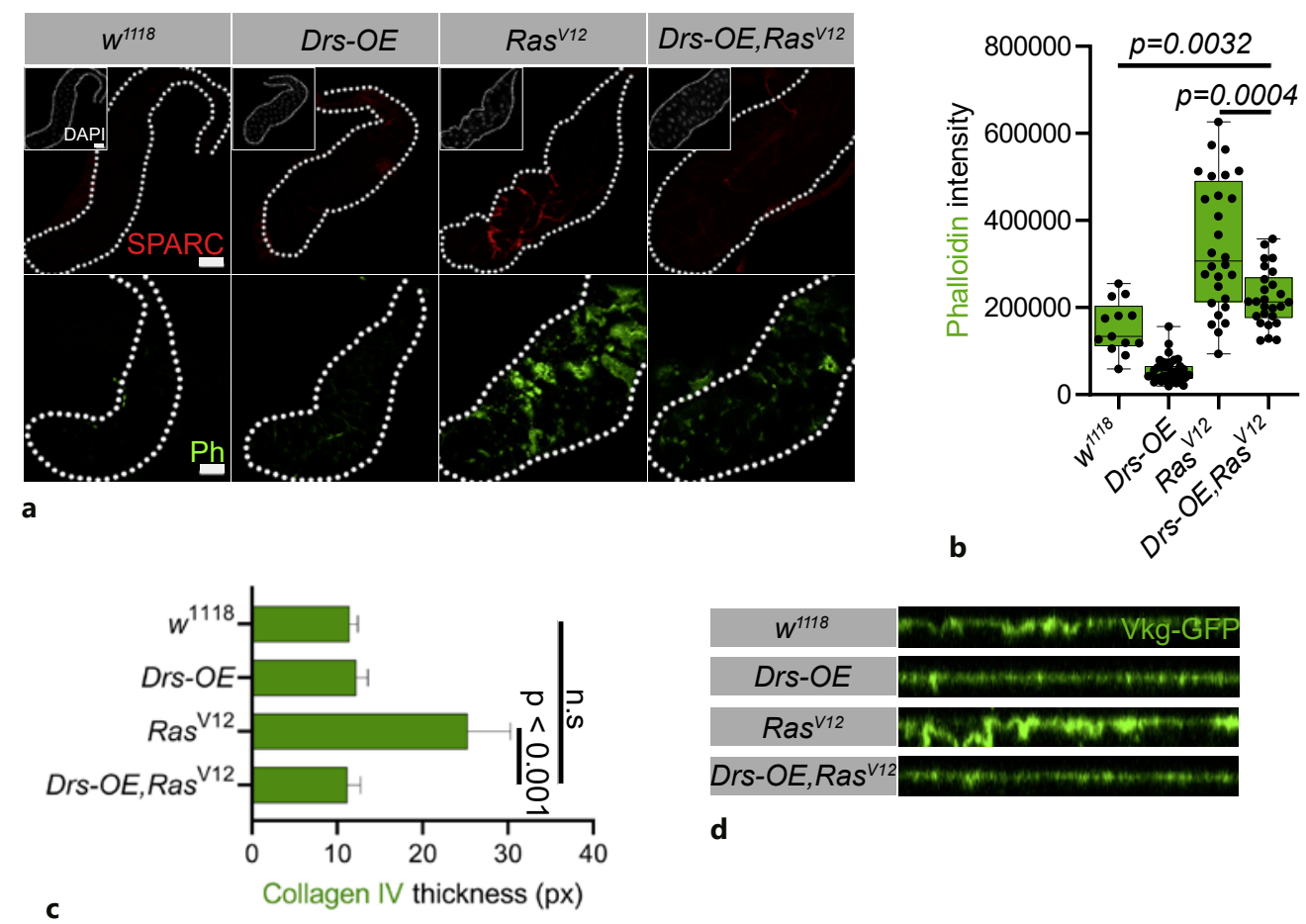

d

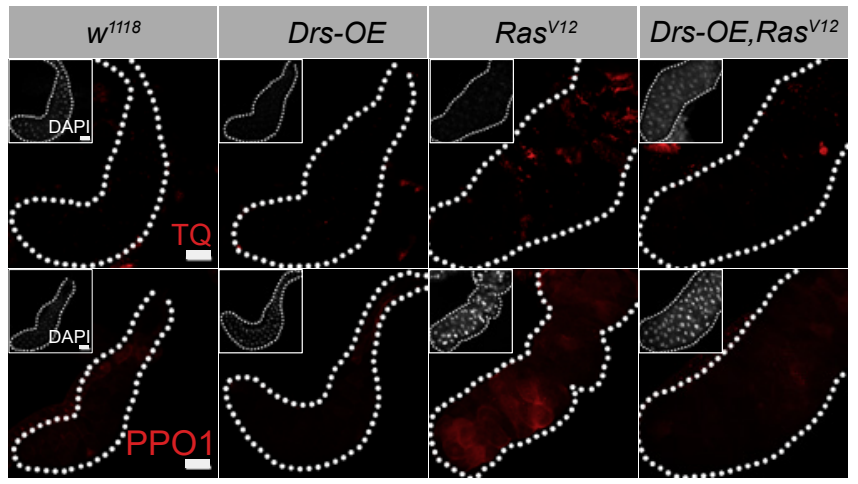

e
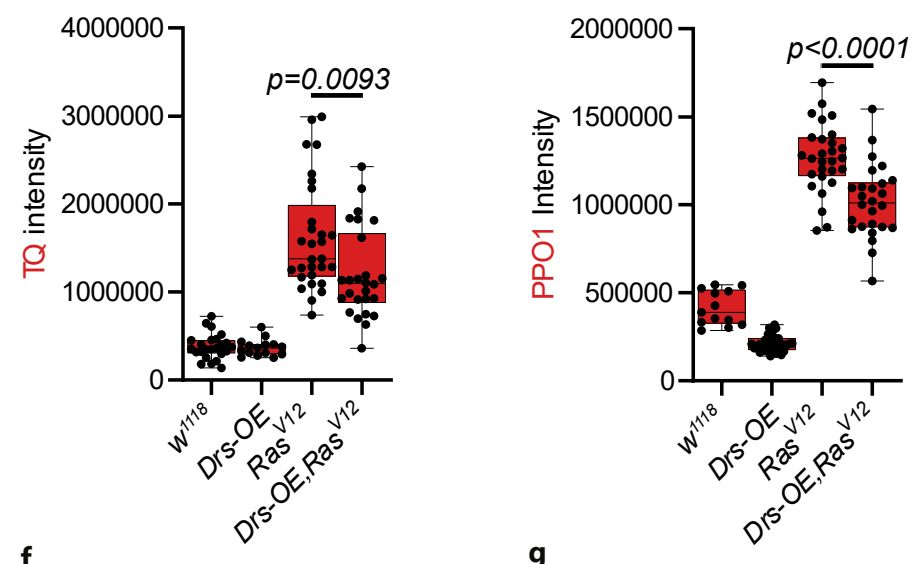
(laminin [Lam], nidogen [Ndg], and perlecan [Pcan]) was analyzed using specific antibodies without detergent on optical sections close to the surface of SGs where the BM is located (Fig. 1a, extracellular) and in the presence of detergent on deeper sections (Fig. 1a, extra/intracellular). Under both conditions, the regular hexagonal pattern of all BM components in wild-type SGs was replaced by a more irregular distribution in $\mathrm{Ras}^{\mathrm{V} 12}$-expressing glands. All 4 proteins displayed an increased the signal intensity compared to wild-type controls (Fig. 1a). To exclude differences in accessibility to antibodies as an explanation for the difference in the signal intensity, we used GFP-tagged collagen IV both for quantification and to measure BM width. This confirmed that compared to control glands, the BM from Ras $^{V 12}$ SGs contained more collagen IV and had also grown thicker (Fig. 1b, c). We conclude that the BM in Ras ${ }^{V 12}$ glands had become disorganized and more extensive, reminiscent of the fibrotic phenotype, which had been observed in Drosophila fat bodies [31] and of mammalian fibrotic lesions. Of note, the fibrotic phenotype was most pronounced in the distal parts of SGs similar to other dysplastic features in the same region.

Although initially used as a control to distinguish between normal and dysplastic SGs, F-actin staining with phalloidin largely mimicked the disorganized distribution of the BM components and was also detected in $\mathrm{Ras}^{\mathrm{V} 12}$ SGs in the absence of detergent on surface sections, indicating that some F-actin may have obtained access to the extracellular compartment (Fig. 1d; quantified in online suppl. Fig. 1b). This was further confirmed by showing significant covariation between $\mathrm{F}$-actin and SPARC on the surface of whole glands (Fig. 1e, f). Additionally, by analyzing Z-scanned SGs, we observed a moderate SPARC-phalloidin colocalization (Fig. 1g). Thus, we find that in the distal part of Ras ${ }^{V 12}$ SGs, BM components are redistributed in concert leading to a fibrotic phenotype including F-actin, part of which may leak out from SG cells and associate with the BM.

Fig. 5. The epithelial character and production of secreted proteins is restored upon co-expressing Drs in $R_{a s}{ }^{V 12}$ glands. a Staining of control (w1118; and Drs-OE), Ras V12 -expressing as well as Drs coexpressing glands (Drs-OE, Ras ${ }^{V 12}$ ) with integrin-specific antibodies, $\mathrm{Ph}$, and $\mathrm{Dlg}$ shows a partial reversion to an epithelial phenotype. $\mathbf{b}$ The production of Sgs3 (Sgs3-GFP) is restored in Drs-OE, Ras $^{V 12}$ glands compared to Ras ${ }^{V 12}$ glands (quantified in c: $p<$ 0.0001 ) in line with the restoration of the SG lumen (detected with

\section{The Immune System Targets Dysplastic Salivary} Glands

To assess the influence of hemostasis on fibrosis, we first measured the activity of Drosophila transglutaminase, which is a key clotting factor and has been shown to target intruders such as bacteria and insect pathogenic nematodes [26]. Mammalian TGs are known to be activated in fibrotic lesions in several organs [13, 14, 58, 59]. Activity of the single Drosophila TG was detected with an antibody against the covalent $\varepsilon$-( $($-L-glutamyl)-L-lysine links that are created by TG and, to focus on extracellular TG, we used non-permeabilized SGs and surface sections (Fig. 2). Compared to wild-type glands, significantly higher TG activity was detected on Ras ${ }^{V 12}$ SGs, indicating that - similar to microbial intruders - dysplastic glands are targeted by TG (Fig. 2a, b). In contrast to wild type, where it was faint, TG activity in Ras ${ }^{V 12}$ SGs was found to covary (Fig. 2c) and moderately colocalize with the phalloidin intensity (Fig. 2d). In addition to TG, tiggrin, which is also part of Drosophila hemolymph clots [60], was recruited to Ras $^{V 12} \mathrm{SG}$, further confirming that hemostasis is activated against dysplastic SGs (online suppl. Fig. 1c, d).

Ultimately, coagulation of hemolymph, the formation of nodules, and the encapsulation of larger objects result in the recruitment and activation of PPO. During coagulation, this follows TG activation [22]. To test whether PPOs are also recruited to dysplastic Ras ${ }^{12}$ glands, we used antibodies specific for PPO1 and PPO2, the 2 PPOs expressed by crystal cells and found that both of them were detected on $\mathrm{Ras}^{\mathrm{V} 12}$-expressing glands (online suppl. Fig. 1e-g). Further analysis showed that PPO1 intensity and phalloidin staining covaried, whereas $\mathrm{PPO} 2$ did not (online suppl. Fig. 1h, i). In summary, these data show that beyond induction of antimicrobial peptides and hemocyte recruitment [46], Ras $^{V 12}$ SGs display local activation of the hemostatic system. This includes structural clot components, such as tiggrin, as well as enzymatic activities, such as transglutaminase, followed by recruitment of phenoloxidases.
$\mathrm{Ph})$. d Western blot analysis shows increased production of Eig71Ee (gp150, $N=3$ ), in Drs-OE,Ras ${ }^{V 12}$ glands (d: $p<0.0114$ ) (gp150, $N=3$ ). e qRT-PCR analysis of Sgs3 and Eig71Ee shows increased expression in Drs-OE, Ras ${ }^{V 12}$ glands in comparison to Ras $^{V 12}$. Scale bars represent $20 \mu \mathrm{m}$ (a) and $100 \mu \mathrm{m}(\mathbf{b})$. Drs-OE, drosomycin-overexpressing; Dlg, disc-large; SGs, salivary glands; $\mathrm{Ph}$, phalloidin; RT-qPCR, reverse-transcription quantitative PCR; Sgs3, salivary glands secreted protein 3 .

(For figure see next page.) 


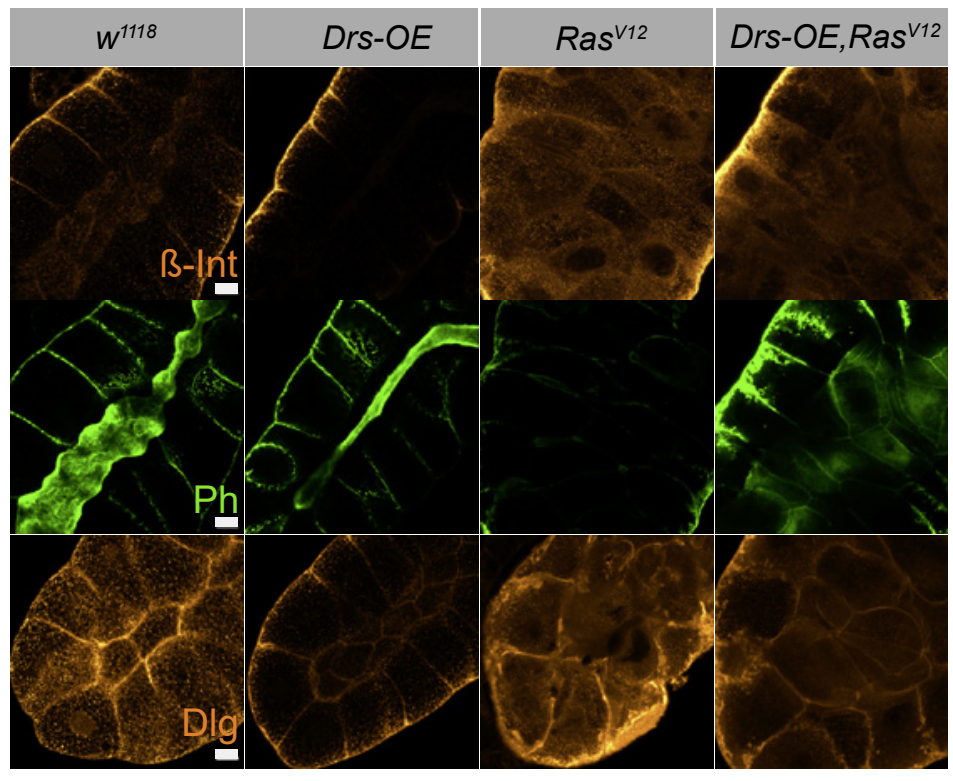

a

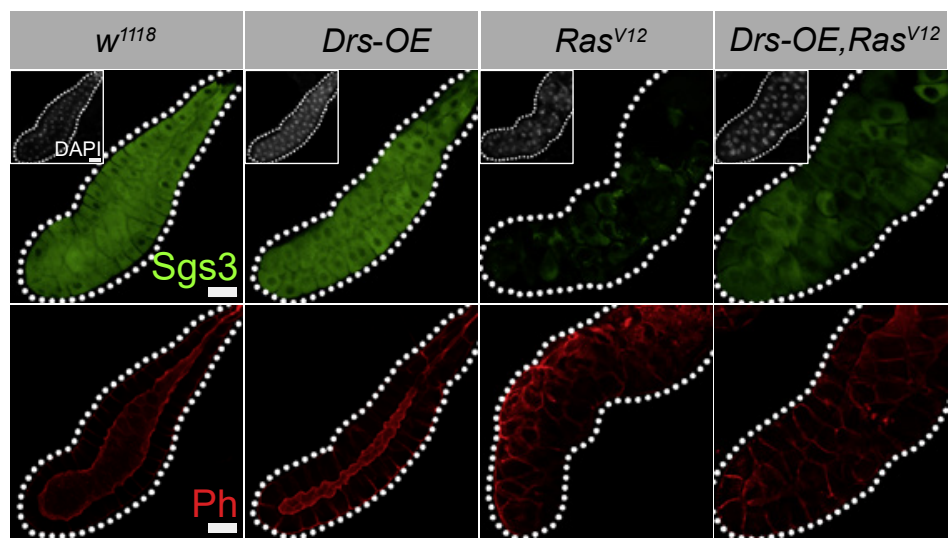

b

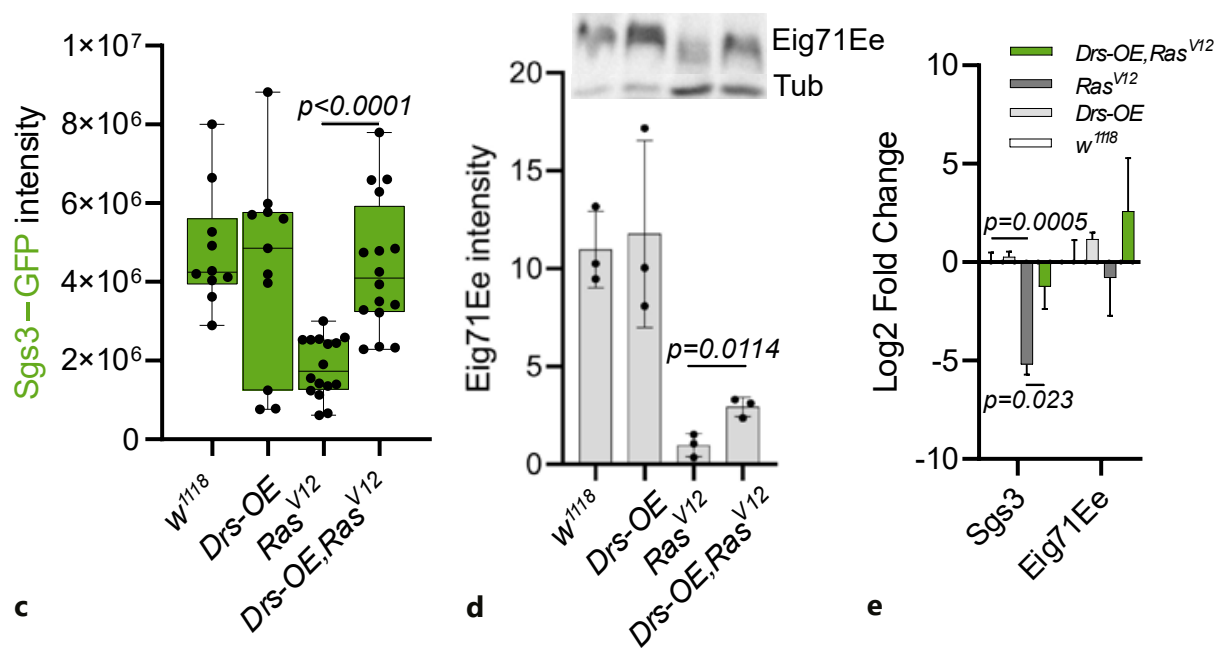


Fig. 6. Drs colocalizes with F-actin in fibrotic lesions. a Drs-HA expressed in wildtype and $\mathrm{Ras}^{\mathrm{V} 12}$-expressing SGs was detected using HA-specific antibodies as well as Phalloidin. Then upper ROI insets (a: yellow) are magnified in the lower panels. b Partial overlap between the signals was confirmed using confocal microscopy including Z-stacks. ROI inset (b: yellow) displays an unprocessed Z-stack of Drs-HA (red) and $\mathrm{Ph}$ (green). Drs, drosomycin; SGs, salivary glands; ROI, region of interest; Drs-HA, HA-tagged Drs; Ph, phalloidin.

An Antimicrobial Peptide Reverts Fibrosis

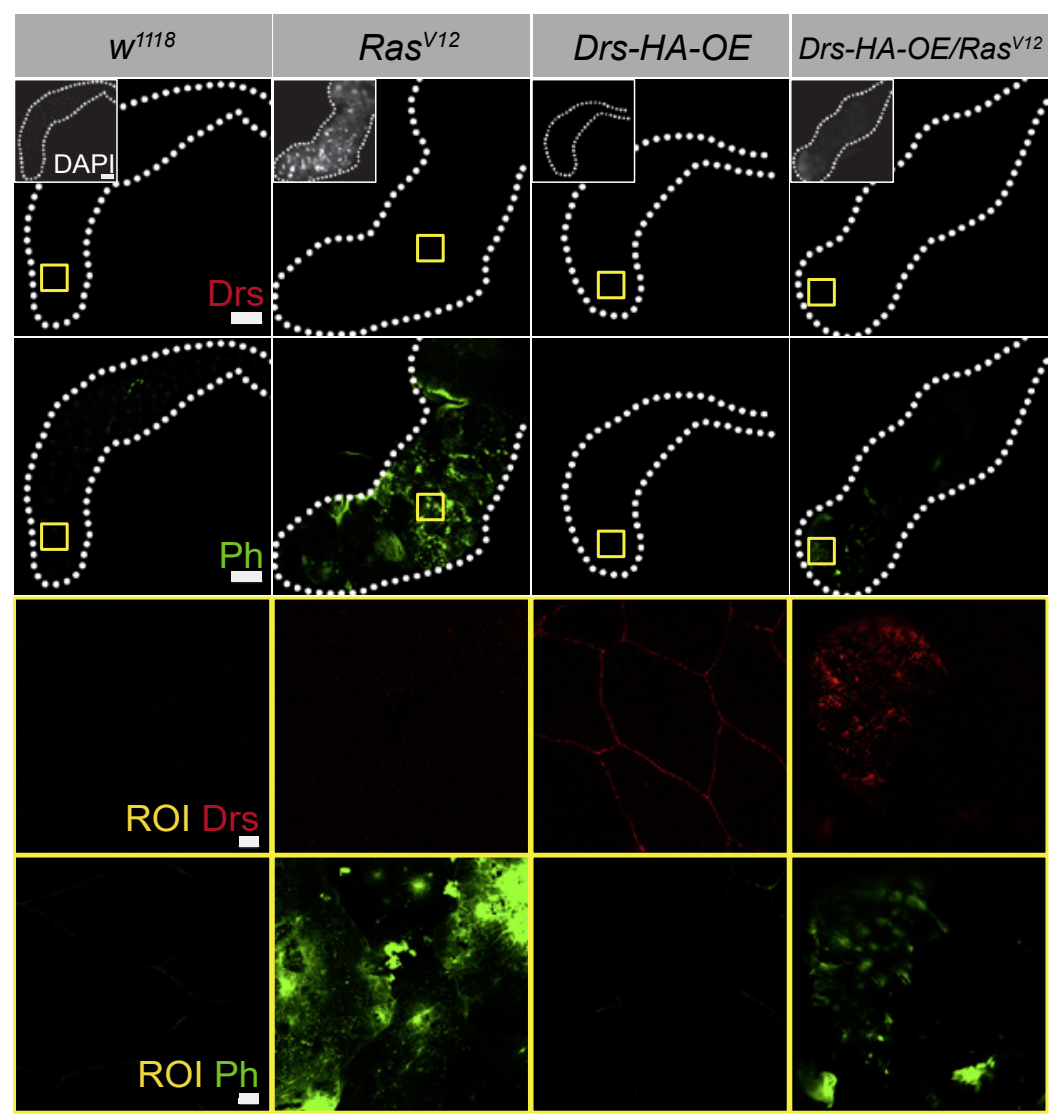

a

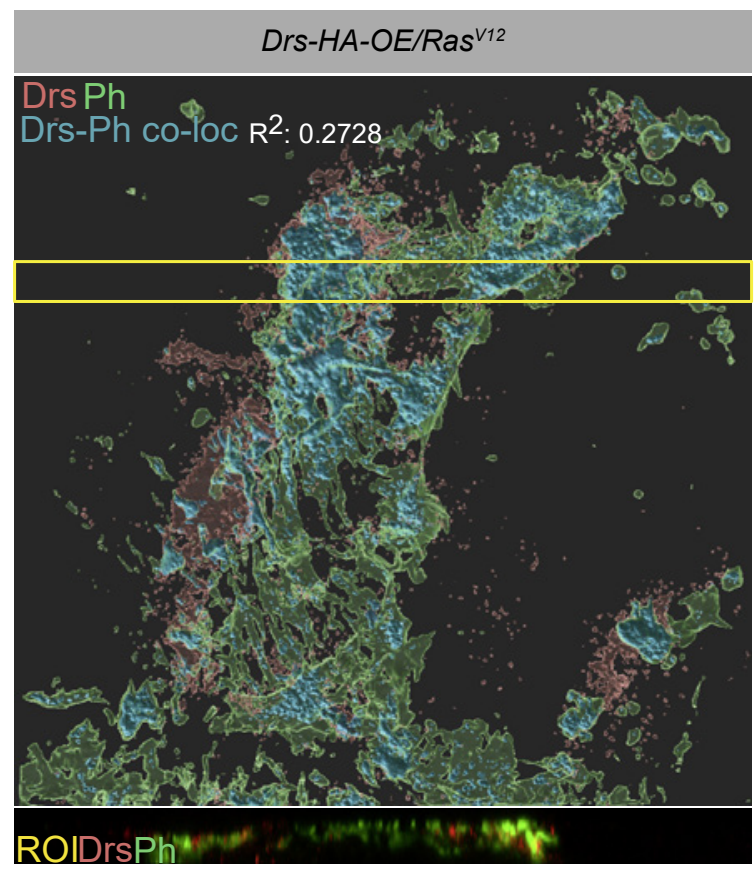

b 


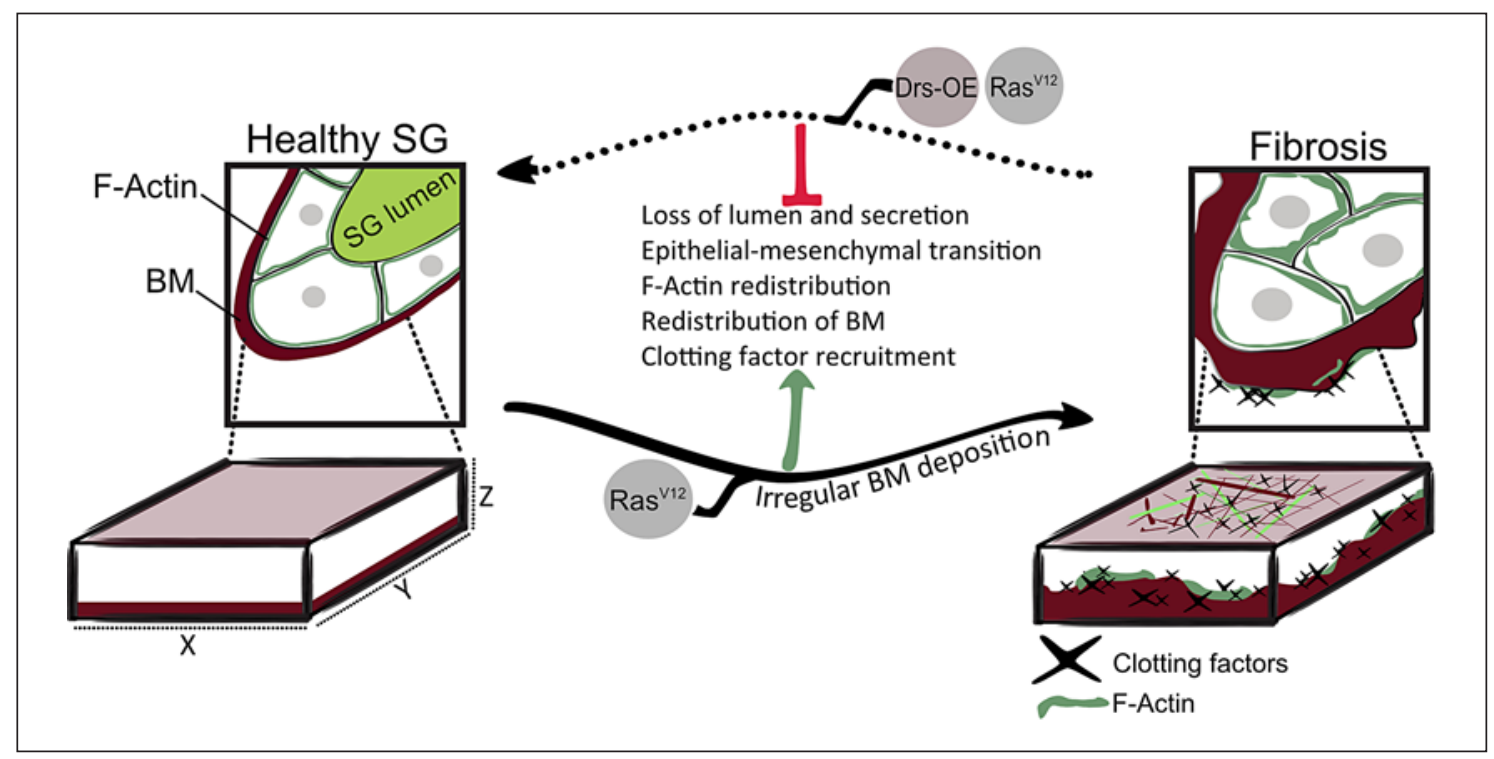

Fig. 7. Fibrosis in SGs, and its reversal through Drs expression. The BM (represented below as in confocal stacks) of $\mathrm{Ras}^{\mathrm{V} 12}$-expressing SGs shows several features of fibrotic lesions, which are substantially reversed upon overexpression of the antimicrobial peptide Drs. Fibrotic lesions incorporate clotting factors from the hemolymphfacing (basal) layer and F-actin from underlying SG cells (see text for further details). Drs, drosomycin; SGs, salivary glands; BM, basement membrane.

\section{Defective Secretion in the Dysplastic Gland}

Having observed fibrosis in dysplastic glands prompted us to investigate the integrity and secretory potential of SGs. As indicated by [39], in addition to a disrupted $\mathrm{BM}$, a second precondition for activation of an inflammatory reaction against the aberrant tissue is a loss of apicobasal polarity. To test whether SG epithelial cells had undergone similar changes, we assessed the distribution of $ß$-integrin, F-actin, and disc-large (Dlg) in permeabilized SGs. B-integrin, one of the receptors for BM components, shows an even surface expression and enrichment at the basal side in wild type SG cells. This pattern had been lost upon $\operatorname{Ras}^{V 12}$ expression, together with a complete loss of the SG lumen detected by phalloidin staining (Fig. 3a). Similarly, the regular hexagonal pattern detected with Dlg-specific antibodies was replaced by a weaker irregular pattern in $\mathrm{Ras}^{\mathrm{V} 12} \mathrm{SGs}$. To test the secretory potential of $R^{V}{ }^{V 12}$ SGs, we assessed the secretion of 2 known SG secretory proteins,salivary glands secreted protein 3 (Sgs3) and Eig71Ee [61, 62]. We first investigated the intensity levels of Sgs3 using a GFP-tagged version under its endogenous promoter. In comparison to control SGs, the dysplastic glands displayed lower Sgs3 levels, in line with the absence of a lumen (Fig. 3b, c). Western blotting and Coomassie staining both revealed lower levels of Eig71Ee in $\mathrm{Ras}^{V 12}$ glands than in control glands (Fig. 3d; online suppl. Fig. 2a). Altogether, dysplastic glands displayed a loss of epithelial character and produced lower amounts of 2 main secretory proteins. Nevertheless, most proteins were still shared with wild type glands and no general degradation was observed (online suppl. Fig. 2a).

An Antimicrobial Peptide Reverts BM Dysplasia, Loss of Epithelial Character, and Secretion

We had previously found that Drs is expressed most strongly in the proximal region of Ras $^{V 12}$ glands, a region which displayed fewer signs of fibrosis and looked more similar to wild type SGs. We also managed to revert collagen IV deregulation by expressing Drs across the whole glands including the strongly affected distal part [46], while expression of control GFP [29] and membranebound RFP [46] under the same UAS control had no such effects. Therefore, we wondered whether the fibrotic distribution of other BM components was rescued upon forced Drs expression across the whole glands. Indeed, in Drs-overexpressing (OE) Ras ${ }^{\mathrm{V} 12}$ SGs, SPARC, Lam, Ndg, Pcan, and actin displayed a more regular localization, closer to the wild type situation in surface sections (Fig. 4a, b; online suppl. Fig. 2b). This was not observed upon RFP overexpression excluding a dilution effect due to the presence of dual UAS targets (online suppl. Fig. 2d). In line with the more regular distribution of BM components, 
BM thickness in Drs-OE Ras $^{V 12}$ SGs were also reduced to wild type levels (Fig. 4c, d). Moreover, transglutaminase activity and PPO1 binding (Fig. 4e-g) decreased, although not completely, when compared to $\operatorname{Ras}^{V 12}$-expressing SGs, whereas PPO2 (online suppl. Fig. 2c) did not revert to wild type levels. At the same time, staining with phalloidin confirmed that F-actin had been reduced to almost wild type levels (Fig. 4b).

To examine the secretory activity in normal, $\mathrm{Ras}^{\mathrm{V12}}$ expressing, and Drs-OE SGs, we compared the SG histology and the production of Sgs3 and Eig71Ee. In line with the renewal of a more normal BM morphology and the restoration of the epithelial character, as assayed by integrin, Dlg, and phalloidin staining (Fig. 5a), the lumen of Drs-OE, $\operatorname{Ras}^{V 12}$ SGs was also partially restored allowing production of both Sgs3 (Fig. 5b, c, e) and Eig71Ee (Fig. 5d, e), in comparison to the Ras ${ }^{V 12}$ glands (Fig. 5b). Sgs3 levels in Ras $^{V 12}$ SGs were not restored when RFP was co-expressed as a negative control (online suppl. Fig. 2f). Both Western blots (Fig. 5d) confirmed higher levels of Eig71Ee in Drs-OE, Ras ${ }^{\text {V12 }}$ glands.

\section{Drs Localization in Fibrotic Lesions}

To detect whether Drs is properly located to interfere with the formation of fibrotic lesions in $\mathrm{Ras}^{\mathrm{V} 12} \mathrm{SGs}$, we used an HA-tagged version (Drs-HA) to analyze surface sections (Fig. 6). Since it has previously been shown that AMPs have the potential to bind actin [63] and based on our own results (see above), we used phalloidin as a proxy to identify fibrotic lesions. Signals for both phalloidin and Drs-HA were detected in Ras $^{V 12}$ SGs and a weak signal upon expression of Drs-HA alone in a wild type background (Fig. 6a). In both cases, Drs-HA overlapped with the phalloidin signal, indicating partial colocalization with F-actin, which was confirmed in Z-sections (Fig. 6b). Taken together, the distribution of Drs in $\mathrm{Ras}^{V 12} \mathrm{SGs}$ is compatible with its inhibitory effect on fibrotic lesions.

\section{Discussion}

We show that expression of a dominant-active form of an oncogene induces a fibrotic phenotype at the BM of Drosophila SGs, a highly active secretory organ (summarized in Fig. 7). In contrast to other Drosophila fibrosis models, the redistribution of BM components, which are primarily produced in the fat body ([38], see also online suppl. Table 2) and deposited onto the internal organs, is most likely a secondary consequence of SG dysplasia. Although we observe an increase in signal intensity for all
BM components in Ras $^{V 12}$ SGs, this appears not to be a consequence of transcriptional activation, since the BM components are only poor if at all induced in the fat body of Ras ${ }^{V 12}$ larvae (see online suppl. Table 2). As a proxy for BM components, SPARC is found associated with extracellular F-actin, which appears to be released from the dysplastic cells either SG cells or rupturing crystal cells [22]. When analyzing, transglutaminase activity as a proxy for hemostasis, we found increased levels in Ras ${ }^{V 12}$ SGs. Similar to what happens during wound closure in flies, TG activation was followed by recruitment of Phenoloxidase, although in this case only the PPO1 signal covaried with phalloidin staining of F-actin. Taken together we detect fibrotic lesions, which contain BM components, TG activity, PPO1, and extracellular F-actin. These findings are in line with the proposed model for fibrotic lesions as unabated wound healing. Although we were initially motivated by a possible hemostatic/immune function of TG, the single Drosophila TG may play a slightly different role during fibrosis similar to mammalian tissue transglutaminase (TG2), which has been shown to aggravate fibrosis in several organs due to its cross-linking activity $[13,14,58,59]$. SG fibrosis affects the normal secretory function of SGs as shown here by: (1) a loss of the epithelial character of SG cells, (2) the collapse of the SG lumen, and (3) reduced production of 2 secretory proteins (Sgs3 and Eig71Ee).

Supporting our previous observations that single expression of the AMP Drs rescues several features of the dysplastic phenotype [46], we found that upon Drs overexpression, the formation of fibrotic lesions at the $\mathrm{BM}$ is substantially reduced and tissue integrity is largely restored including a partial reversion to an epithelial character of SG cells and restoration of secretory activity (summarized in Fig. 7). This is paralleled by a reduction in hemostatic/immune activation including (1) fewer TG cross-links and (2) a reduction in recruitment of PPO1, but not PPO2. These findings support the notion that early hemostatic components are recruited toward fibrotic foci, similar to wounds were PPO1 and TG activity have been shown to precede PPO2, which is subsequently released by rupture of crystal cells [22, 64].

Finally, we observe that Drs colocalizes with F-actin in fibrotic lesions similar to the mammalian AMP LL-37 which has previously been shown to interact with F-actin $[63,65]$ with different effects, including protection from microbial degradation [66], but also inhibition of the antimicrobial activity [67]. Due to high background staining, we were unable to determine whether Drs is also secreted apically into the SG lumen. Therefore, we do not 
know whether Drs equally influences the apical and basal secretion of SG cells. For the basal localization, we propose a scenario where secreted Drs reduces the formation of fibrotic plaques by interfering with the aggregation of $\mathrm{BM}$ components. These may include particulate actin (Factin), which, once released from cells, is known to have deleterious effects, for example, during sepsis [68], by acting as a procoagulant [69], and through inhibition of macrophage defenses [70]. These effects are counteracted by actin-scavenging systems [69], which include soluble gelsolin [71], vitamin D-binding protein [72], and - as proposed here - Drs. In line with potential role as damage-associated molecular patterns [73-75], cytosolic proteins have been shown to activate immunity in flies [76, 77]. Irrespective of its target in fibrotic foci, the anti-fibrotic effects of Drs are of clinical interest and may include other AMPs, such as the bee AMP melittin [78-80], which restores the epithelial character [81] similar to what we observe. Taken together, the data presented here support the concept that dysplasia of tumor cells supports the formation of fibrotic aggregates $[6,10]$. The recruitment of both TG and PO, which are known players in hemolymph coagulation, lends further support to the concept that tumors induce a chronic procoagulatory state $[82,83]$ and adds the notion that AMPs have the potential to revert this phenotype.

\section{Acknowledgements}

We thank Stina Höglund, Chris Molenaar, and the imaging facility at Stockholm University for support with all aspects of microscopy. We also thank the anonymous reviewers for their constructive feedback, Roger Karlsson for his critical input, and the late Thomas Stössel for drawing our attention to actin-scavenging systems.

\section{Statement of Ethics}

No approval of studies involving animals was required.

\section{Conflict of Interest Statement}

The authors declare no conflict of interest.

\section{Funding Sources}

This work was supported by the Swedish Research Council (VR-2010-5988 and VR 2016-04077) and the Swedish Cancer Foundation (CAN 2010/553 and CAN 2013/546) to UT and the Eric Philipp Sörensen Stiftelse to SB.

\section{Author Contributions}

Experiment design: D.K., S.B., and U.T.; experimental work: D.K., C.K., and S.B.; raising funding: S.B. and U.T.; manuscript drafting: D.K., S.B., and U.T.

\section{References}

1 Broadie K, Baumgartner S, Prokop A. Extracellular matrix and its receptors in Drosophila neural development. Dev Neurobiol. 2011 Nov;71(11):1102-30.

2 Pastor-Pareja JC. Atypical basement membranes and basement membrane diversity: what is normal anyway? J Cell Sci. $2020 \mathrm{Apr}$ 21;133(8):jcs241794.

3 Bonnans C, Chou J, Werb Z. Remodelling the extracellular matrix in development and disease. Nat Rev Mol Cell Biol. 2014 Dec;15(12): 786-801.

4 Theocharis AD, Manou D, Karamanos NK. The extracellular matrix as a multitasking player in disease. Febs J. 2019 Aug;286(15): 2830-69.

5 Walker C, Mojares E, Del Rio Hernandez A Role of extracellular matrix in development and cancer progression. Int J Mol Sci. 2018 Oct 4;19(10):3028.

6 Rockey DC, Bell PD, Hill JA. Fibrosis: a common pathway to organ injury and failure. $\mathrm{N}$ Engl J Med. 2015 Jul 2;373(1):96.

7 Hoye AM, Erler JT. Structural ECM components in the premetastatic and metastatic niche. Am J Physiol Cell Physiol. 2016 Jun 1; 310(11):C955-67.

8 Weniger M, Honselmann KC, Liss AS. The extracellular matrix and pancreatic cancer: a complex relationship. Cancers. 2018 Sep 6; 10(9):316.

9 Wynn TA. Cellular and molecular mechanisms of fibrosis. J Pathol. 2008 Jan;214(2): 199-210.

10 Wynn TA, Ramalingam TR. Mechanisms of fibrosis: therapeutic translation for fibrotic disease. Nat Med. 2012 Jul 6;18(7): 1028-40.

11 Zhou Y, Peng H, Sun H, Peng X, Tang C, Gan $\mathrm{Y}$, et al. Chitinase 3-like 1 suppresses injury and promotes fibroproliferative responses in Mammalian lung fibrosis. Sci Transl Med. 2014 Jun 11;6(240):240ra76.

12 George PM, Wells AU, Jenkins RG. Pulmonary fibrosis and COVID-19: the potential role for antifibrotic therapy. Lancet Respir Med. 2020 Aug;8(8):807-15.

13 Lin CH, Chen J, Zhang Z, Johnson GV, Cooper AJ, Feola J, et al. Endostatin and transglutaminase 2 are involved in fibrosis of the ag- ing kidney. Kidney Int. 2016 Jun;89(6):128192.

14 Philp CJ, Siebeke I, Clements D, Miller S, Habgood A, John AE, et al. Extracellular matrix cross-linking enhances fibroblast growth and protects against matrix proteolysis in lung fibrosis. Am J Respir Cell Mol Biol. 2018 May;58(5):594-603.

15 Lemaitre B, Hoffmann J. The host defense of Drosophila melanogaster. Annu Rev Immunol. 2007;25:697-743.

16 Gold KS, Brückner K. Macrophages and cellular immunity in Drosophila melanogaster. Semin Immunol. 2015 Dec;27(6):357-68

17 Bergman P, Seyedoleslami Esfahani S, Engström Y. Drosophila as a model for human diseases-focus on innate immunity in barrier epithelia. Curr Top Dev Biol. 2017;121:2981.

18 Keehnen NLP, Rolff J, Theopold U, Wheat CW. Insect antimicrobial defences: a brief history, recent findings, biases, and a way forward in evolutionary studies. In: Ligoxygakis $\mathrm{P}$, editor. Insect immunity. Advances in insect physiology. 2017. p. 1-33. 
19 Sheehan G, Garvey A, Croke M, Kavanagh K. Innate humoral immune defences in mammals and insects: the same, with differences? Virulence. 2018;9(1):1625-39.

20 Fehlbaum P, Bulet P, Michaut L, Lagueux M, Broekaert WF, Hetru C, et al. Insect immunity. Septic injury of Drosophila induces the synthesis of a potent antifungal peptide with sequence homology to plant antifungal peptides. J Biol Chem. 1994 Dec 30;269(52): 33159-63.

21 Hillyer JF. Insect immunology and hematopoiesis. Dev Comp Immunol. 2016 May;58: $102-18$.

22 Schmid MR, Dziedziech A, Arefin B, Kienzle $\mathrm{T}$, Wang Z, Akhter $\mathrm{M}$, et al. Insect hemolymph coagulation: kinetics of classically and non-classically secreted clotting factors. Insect Biochem Mol Biol. 2019 Jun;109:63-71.

23 Cho B, Yoon SH, Lee D, Koranteng F, Tattikota SG, Cha N, et al. Single-cell transcriptome maps of myeloid blood cell lineages in Drosophila. Nat Commun. 2020 Sep 8;11(1): 4483.

24 Tattikota SG, Cho B, Liu Y, Hu Y, Barrera V, Steinbaugh MJ, et al. A single-cell survey of Drosophila blood. Elife. 2020 May 12:9.

25 Theopold U, Krautz R, Dushay MS. The Drosophila clotting system and its messages for mammals. Dev Comp Immunol. 2014 Jan; 42(1):42-6.

26 Wang Z, Wilhelmsson C, Hyrsl P, Loof TG, Dobes P, Klupp M, et al. Pathogen entrapment by transglutaminase: a conserved early innate immune mechanism. PLoS Pathog. 2010;6(2):e1000763.

27 Dziedziech A, Schmid M, Arefin B, Kienzle T, Krautz R, Theopold U. Data on Drosophila clots and hemocyte morphologies using GFPtagged secretory proteins: Prophenoloxidase and transglutaminase. Data Brief. 2019 Aug; 25:104229.

28 Markus R, Laurinyecz B, Kurucz E, Honti V, Bajusz I, Sipos B, et al. Sessile hemocytes as a hematopoietic compartment in Drosophila melanogaster. Proc Natl Acad Sci U S A. 2009 Mar 24;106(12):4805-9.

29 Hauling T, Krautz R, Markus R, Volkenhoff A, Kucerova L, Theopold U. A Drosophila immune response against Ras-induced overgrowth. Biol Open. 2014;3(4):250-60.

30 Minakhina S, Steward R. Melanotic mutants in Drosophila: pathways and phenotypes. Genetics. 2006 Sep;174(1):253-63.

31 Zang Y, Wan M, Liu M, Ke H, Ma S, Liu LP, et al. Plasma membrane overgrowth causes fibrotic collagen accumulation and immune activation in Drosophila adipocytes. Elife. 2015;4:e07187.

32 Le Parco Y, Knibiehler B, Cecchini JP, Mirre C. Stage and tissue-specific expression of a collagen gene during Drosophila melanogaster development. Exp Cell Res. 1986 Apr; 163(2):405-12.

33 Kusche-Gullberg M, Garrison K, MacKrell AJ, Fessler LI, Fessler JH. Laminin A chain: expression during Drosophila development and genomic sequence. EMBO J. 1992 Dec; 11(12):4519-27.

34 Yasothornsrikul S, Davis WJ, Cramer G, Kimbrell DA, Dearolf CR. viking: identification and characterization of a second type IV collagen in Drosophila. Gene. 1997 Oct 1; 198(1-2):17-25.

35 Martinek N, Shahab J, Saathoff M, Ringuette M. Haemocyte-derived SPARC is required for collagen-IV-dependent stability of basal laminae in Drosophila embryos. J Cell Sci. 2008 May 15;121(Pt 10):1671-80.

36 Van De Bor V, Zimniak G, Papone L, Cerezo D, Malbouyres M, Juan T, et al. Companion blood cells control ovarian stem cell niche microenvironment and homeostasis. Cell Rep. 2015 Oct 20;13(3):546-60.

37 Duncan S, Delage S, Chioran A, Sirbu O, Brown TJ, Ringuette MJ. The predicted collagen-binding domains of Drosophila SPARC are essential for survival and for collagen IV distribution and assembly into basement membranes. Dev Biol. 2020 May 15;461(2): 197-209.

38 Pastor-Pareja JC, Xu T. Shaping cells and organs in Drosophila by opposing roles of fat body-secreted Collagen IV and perlecan. Dev Cell. 2011 Aug 16;21(2):245-56.

39 Kim MJ, Choe KM. Basement membrane and cell integrity of self-tissues in maintaining Drosophila immunological tolerance. PLoS Genet. 2014 Oct;10(10):e1004683.

40 Vaughan L, Marley R, Miellet S, Hartley PS. The impact of SPARC on age-related cardiac dysfunction and fibrosis in Drosophila. Exp Gerontol. 2018 Aug;109:59-66.

41 Kerman BE, Cheshire AM, Andrew DJ. From fate to function: the Drosophila trachea and salivary gland as models for tubulogenesis. Differentiation. 2006 Sep;74(7):326-48.

42 Berry DL, Baehrecke EH. Growth arrest and autophagy are required for salivary gland cell degradation in Drosophila. Cell. 2007 Dec 14; 131(6):1137-48.

43 Pirraglia C, Myat MM. Genetic regulation of salivary gland development in Drosophila melanogaster. Front Oral Biol. 2010;14:3247.

44 Duan J, Zhao Y, Li H, Habernig L, Gordon $\mathrm{MD}$, Miao X, et al. Bab2 functions as an ecdysone-responsive transcriptional repressor during Drosophila development. Cell Rep. 2020 Jul 28;32(4):107972.

45 Imler JL, Bulet P. Antimicrobial peptides in Drosophila: structures, activities and gene regulation. Chem Immunol Allergy. 2005;86: $1-21$.

46 Krautz R, Khalili D, Theopold U. Tissue-autonomous immune response regulates stress signaling during hypertrophy. Elife. 2020 Dec 30;9:9.

47 Razzell W, Wood W, Martin P. Swatting flies: modelling wound healing and inflammation in Drosophila. Dis Model Mech. 2011 SepOct;4(5):569-74.

48 Morin X, Daneman R, Zavortink M, Chia W. A protein trap strategy to detect GFP-tagged proteins expressed from their endogenous loci in Drosophila. Proc Natl Acad Sci U S A. 2001 Dec 18;98(26):15050-5.

49 Bischof J, Björklund M, Furger E, Schertel C, Taipale J, Basler K. A versatile platform for creating a comprehensive UAS-ORFeome library in Drosophila. Development. 2013 Jun; 140(11):2434-42

50 Attrill H, Falls K, Goodman JL, Millburn GH, Antonazzo G, Rey AJ, et al. FlyBase: establishing a Gene Group resource for Drosophila melanogaster. Nucleic Acids Res. 2016 Jan 4; 44(D1):D786-92.

51 Kohfeldt E, Maurer P, Vannahme C, Timpl R. Properties of the extracellular calcium binding module of the proteoglycan testican. FEBS Lett. 1997 Sep 15;414(3):557-61.

52 Timpl R. Antibodies to collagens and procollagens. Meth Enzymol. 1982;82(Pt A):47298. A:

53 Wolfstetter G, Dahlitz I, Pfeifer K, Töpfer U, Alt JA, Pfeifer DC, et al. Characterization of Drosophila Nidogen/entactin reveals roles in basement membrane stability, barrier function and nervous system patterning. Development. 2019 Jan 16;146(2):dev168948.

54 Gutzeit HO, Eberhardt W, Gratwohl E. Laminin and basement membrane-associated microfilaments in wild-type and mutant Drosophila ovarian follicles. J Cell Sci. 1991 Dec; 100(Pt 4):781-8

55 Friedrich MV, Schneider M, Timpl R, Baumgartner S. Perlecan domain V of Drosophila melanogaster. Sequence, recombinant analysis and tissue expression. Eur J Biochem. 2000 Jun;267(11):3149-59.

56 Deng H, Bell JB, Simmonds AJ. Vestigial is required during late-stage muscle differentiation in Drosophila melanogaster embryos. Mol Biol Cell. 2010 Oct 1;21(19):3304-16.

57 Krautz R, Khalili D, Theopold U. Tissue-autonomous immune response regulates stress signaling during hypertrophy. eLife. 2020;9: e64919.

58 Wang Z, Stuckey DJ, Murdoch CE, Camelliti P, Lip GYH, Griffin M. Cardiac fibrosis can be attenuated by blocking the activity of transglutaminase 2 using a selective small-molecule inhibitor. Cell Death Dis. 2018 Apr 27; $9(6): 613$

59 Li ZY, Xiao L, Lin G, Tang J, Chen Y, Chen $\mathrm{L}$, et al. Contribution of tissue transglutaminase to the severity of hepatic fibrosis resulting from Schistosoma japonicum infection through the regulation of IL-33/ST2 expression. Parasit Vectors. 2019 Jun 14;12(1): 302

60 Scherfer C, Karlsson C, Loseva O, Bidla G, Goto A, Havemann J, et al. Isolation and characterization of hemolymph clotting factors in Drosophila melanogaster by a pullout method. Curr Biol. 2004 Apr 6;14(7):625-9.

61 Wright LG, Chen T, Thummel CS, Guild GM Molecular characterization of the 71E late puff in Drosophila melanogaster reveals a family of novel genes. J Mol Biol. 1996;255(3): 387-400. 
62 Korayem AM, Fabbri M, Takahashi K, Scherfer C, Lindgren M, Schmidt O, et al. A Drosophila salivary gland mucin is also expressed in immune tissues: evidence for a function in coagulation and the entrapment of bacteria. Insect Biochem Mol Biol. 2004 Dec;34(12): 1297-304.

63 Sol A, Wang G, Blotnick E, Golla R, Bachrach $\mathrm{G}$, Muhlrad A. Interaction of the core fragments of the LL-37 host defense peptide with actin. RSC Adv. 2015;5(13):9361-7.

64 Neyen C, Binggeli O, Roversi P, Bertin L, Sleiman MB, Lemaitre $B$. The Black cells phenotype is caused by a point mutation in the Drosophila pro-phenoloxidase 1 gene that triggers melanization and hematopoietic defects. Dev Comp Immunol. 2015 Jun;50(2):166-74.

65 Sol A, Blotnick E, Bachrach G, Muhlrad A. LL-37 induces polymerization and bundling of actin and affects actin structure. PLoS One. 2012;7(11):e50078.

66 Sol A, Skvirsky Y, Nashef R, Zelentsova K, Burstyn-Cohen T, Blotnick E, et al. Actin enables the antimicrobial action of LL-37 peptide in the presence of microbial proteases. J Biol Chem. 2014 Aug 15;289(33):22926-41.

67 Weiner DJ, Bucki R, Janmey PA. The antimicrobial activity of the cathelicidin LL37 is inhibited by F-actin bundles and restored by gelsolin. Am J Respir Cell Mol Biol. 2003 Jun; 28(6):738-45.

68 Lee PS, Waxman AB, Cotich KL, Chung SW, Perrella MA, Stossel TP. Plasma gelsolin is a marker and therapeutic agent in animal sepsis. Crit Care Med. 2007 Mar;35(3):849-55.

69 Lee WM, Galbraith RM. The extracellular actin-scavenger system and actin toxicity. N Engl J Med. 1992 May 14;326(20):1335-41.
70 Ordija CM, Chiou TT, Yang Z, Deloid GM, de Oliveira Valdo M, Wang Z, et al. Free actin impairs macrophage bacterial defenses via scavenger receptor MARCO interaction with reversal by plasma gelsolin. Am J Physiol Lung Cell Mol Physiol. 2017 Jun 1;312(6): L1018-28.

71 Cohen TS, Bucki R, Byfield FJ, Ciccarelli NJ Rosenberg B, DiNubile MJ, et al. Therapeutic potential of plasma gelsolin administration in a rat model of sepsis. Cytokine. 2011 Jun; 54(3):235-8.

72 Meier U, Gressner O, Lammert F, Gressner AM. Gc-globulin: roles in response to injury. Clin Chem. 2006 Jul;52(7):1247-53.

73 Matzinger P. The danger model: a renewed sense of self. Science. 2002 Apr 12;296(5566): 301-5.

74 Seong SY, Matzinger P. Hydrophobicity: an ancient damage-associated molecular pattern that initiates innate immune responses. Nat Rev Immunol. 2004 Jun;4(6):469-78.

75 Ahrens S, Zelenay S, Sancho D, Hanč P, Kjær $\mathrm{S}$, Feest C, et al. F-actin is an evolutionarily conserved damage-associated molecular pattern recognized by DNGR-1, a receptor for dead cells. Immunity. 2012 Apr 20;36(4):63545.

76 Srinivasan N, Gordon O, Ahrens S, Franz A, Deddouche $\mathrm{S}$, Chakravarty $\mathrm{P}$, et al. Actin is an evolutionarily-conserved damage-associated molecular pattern that signals tissue injury in Drosophila melanogaster. Elife. 2016 Nov 22; 5:5.
77 Gordon O, Henry CM, Srinivasan N, Ahrens S, Franz A, Deddouche S, et al. $\alpha$-actinin accounts for the bioactivity of actin preparations in inducing STAT target genes in Drosophila melanogaster. Elife. 2018 Sep 27;7:7.

78 Yun SW, Bae GS, Kim MS, Park KC, Koo BS, Kim BJ, et al. Melittin inhibits cerulein-induced acute pancreatitis via inhibition of the JNK pathway. Int Immunopharmacol. 2011 Dec;11(12):2062-72.

79 Kim KH, Sung HJ, Lee WR, An HJ, Kim JY, Pak SC, et al. Effects of melittin treatment in cholangitis and biliary fibrosis in a model of xenobiotic-induced cholestasis in mice. Toxins. 2015 Aug 25;7(9):3372-87.

80 An HJ, Kim JY, Kim WH, Han SM, Park KK. The protective effect of melittin on renal fibrosis in an animal model of unilateral ureteral obstruction. Molecules. 2016 Aug 27; 21(9):21.

81 Park JH, Park B, Park KK. Suppression of hepatic epithelial-to-mesenchymal transition by melittin via blocking of $\mathrm{TGF} \beta /$ Smad and MAPK-JNK signaling pathways. Toxins. 2017 Apr 13;9(4):138.

82 Sheth RA, Niekamp A, Quencer KB, Shamoun F, Knuttinen MG, Naidu S, et al. Thrombosis in cancer patients: etiology, incidence, and management. Cardiovasc Diagn Ther. 2017 Dec;7(Suppl 3):S178-85.

83 Abdol Razak NB, Jones G, Bhandari M, Berndt MC, Metharom P. Cancer-associated thrombosis: an overview of mechanisms, risk factors, and treatment. Cancers. 2018 Oct 11; 10(10):380 